\title{
Future Observational and Modelling Needs Identified on the Basis of the Existing Shelf Data
}

J Berlamont, G. Radach, G. Becker, F. Colijn, J. Gekeler, R. W. P. M. Laane, J. Monbaliu, D. Prandle, J. SÜndermann, W. VAN RaAPHORSt, C. S. Yu

\section{Summary}

NOWESP has compiled a vast quantity of existing data from the north-west European shelf. Such a focused task is without precedence. It is now highly recommended that one, or a few national and international data centres or agencies should be chosen and properly supported by the E. U., where all available observational data, incl. the NOWESP data, are collected, stored, regularly updated by the providers of the data, and made available to the researchers. International agreement must be reached on the quality control procedures and quality standards for data to be stored in these data bases. Proper arrangements should be made to preserve the economic value of the data for their "owners" without compromising use of the data by researchers or duplicating data collecting efforts.

The Continental Shelf data needed are concentration fields of temperature, salinity, nutrients, suspended matter and chlorophyll, which can be called "climatological" fields. For this purpose at least one monthly survey on the whole European shelf is needed at least during five years, with a proper spatial resolution, e. g. $1^{\circ}$ by $1^{\circ}$, and at least in those areas where climatological data are now totally lacking. From the modelling point of view an alternative would be the availability of data from sufficiently representative fixed stations on the shelf, with weekly sampling for several years.

It should be realized that there are hardly any data available on the shelf boundaries. Therefore, one should consider a European effort to set up a limited network of stations, especially at the shelf edge, where a limited, selected set of parameters is measured on a long-term basis (time series) for use in modelling and for interpreting long-term natural changes in the marine environment and changes due to human interference (eutrophication, pollutants, climatic changes, biodiversity changes).

The E. U. could foster coordination of nationally organized measuring campaigns in Europe.

Methodologies should be promoted to collect areal distributed data sets through remote sensing (satellite or aircraft-borne) techniques.

The formulations of basic physics should be improved: turbulence must be simulated in a way that more closely represents nature. There is a need for a well validated, detailed shelf circulation model which represents the measured data properly during long-term simulations. Tides must always be included since they are important for mixing. A detailed North Atlantic ocean circulation model should be developed to provide proper boundary conditions at the shelf edge.

The physics of exchanges at the shelf edges, between the ocean models and the shelf models should be studied and better formulated.

\section{Zukünftige Anforderungen an die Messung und Modellierung unter Berücksichtigung vorhandener} Schelfdaten (Zusammenfassung)

Im Rahmen von NOWESP wurde eine immense Menge von Daten über den nordwesteuropäischen Schelf zusammengetragen, ein in dieser gezielten Form bisher einmaliges Projekt. Es wird dringend empfohlen, ein oder mehrere nationale oder internationale Datenzentren auszuwählen, die diese Daten komplett speichern und sie regelmäßig durch die Datenlieferanten aktualisieren lassen, um sie der Forschung zugänglich zu machen. Das Projekt sollte von der EU gefördert werden. Es müssen internationale Vereinbarungen über die Qualitätssicherung der zu speichernden Daten getroffen werden. Ferner sollte der wirtschaftliche Wert der Daten für ihre jeweiligen „Eigner" gesichert werden, ohne dadurch den Zugriff anderer Forscher auf die Daten zu behindern; auch sollen auf diese Weise doppelte Datensammlungen vermieden werden.

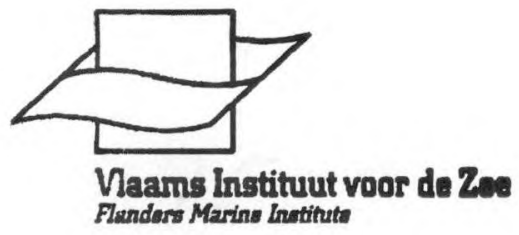


Die benötigten Datenfelder vom Kontinentalschelf konzentrieren sich auf Temperatur, Salzgehalt, Nährstoffe, Schwebstoffe und Chlorophyll, die man als klimatologische Felder bezeichen könnte. Dazu wäre mindestens eine monatliche Meßkampagne auf dem gesamten europäischen Schelf über einen Zeitraum von fünf Jahren erforderlich, und zwar mit einer geeigneten räumlichen Auflösung von z. B. $1^{\circ}$ mal $1^{\circ}$ zumindest in den Gebieten, für die bisher keine klimatologischen Daten vorliegen. Für Modellierungszwecke würden sich alternativ auch Daten von repräsentativen Schelfstationen mit wöchentlicher Probenahme über mehrere Jahre eignen.

Da bisher kaum Daten von den Schelfrändern vorliegen, wäre im europäischen Rahmen die Schaffung eines gemeinsamen Stationsnetzes vor allem am Schelfrand denkbar, um Zeitreihen bestimmter Parameter für Modellierungszwecke und die Erfassung langfristiger natürlicher und anthropogener Änderungen der Meeresumwelt (Eutrophierung, Schadstoffe, Klimaänderungen, Artenreichtum) zu erhalten.

Die EU könnte die Koordination nationaler europäischer Meßkampagnen fördern. Methoden der großflächigen Datensammlung per Fernerkundung (Satellit oder Flugzeug) sollten gefördert werden.

Eine Verbesserung der Darstellung physikalischer Vorgänge ist notwendig: Turbulenzen müssen naturgetreuer simuliert werden. Es fehlt ein gut validiertes, detailliertes Schelfzirkulationsmodell, das Meßdaten in Langzeitsimulationen adäquat wiedergibt. Die Gezeiten müssen immer einbezogen werden, da sie bei Mischungsvorgängen eine große Rolle spielen. Es sollte ein detailliertes Strömungsmodell für den Nordatlantik entwickelt werden, um geeignete Randbedingungen für den Schelfrand zu erhalten. Die physikalischen Austauschbedingungen an den Schelfrändern zwischen den Ozean- und Schelfmodellen sollten besser formuliert werden.

1

\section{Objective}

Task B3 (from the technical annex to NOWESP) is formulated as follows:

From the statistical analysis of the data sets and the assessments of the fluxes and budgets it will become clear what the major data gaps are and what problems may be expected in modelling the shelf fluxes. Through concerted actions of experts on analysis of field data and numerical flux modelling the future observational and modelling needs will be indicated.

\section{Introduction}

During the NOWESP (NOrth West European Shelf Project), a large observational data set on different hydrographical, chemical and biological parameters has been compiled for the N. W. European Shelf from the NOWESP partner institutes and from other authorities (VAN LEUSSEN et al. [1996], GEKELER AND RADACH [1996a], RADACH et al. [1996c]).

The North-West European shelf covers the area within the $200 \mathrm{~m}$ depth contour, including the French shelf, the Irish Sea, the Celtic Sea, the
Channel, the North Sea, the shelf west of the British isles, the Norwegian Trench, the Skagerrak, the Kattegat, and the westernmost part of the Baltic Sea.

For about ten key parameters, namely temperature, salinity, phosphate, nitrate, nitrite, ammonium, silicate, particulate suspended matter and chlorophyll, data on long-term changes (20 to 30 years) and geographical distribution have been collected.

Another source of data is several (real time) operational numerical models available in Europe to predict North Sea tides, surges, waves, currents and water fluxes and, to some extent, temperature and salinity (YU et al. [1995], SMITH AND DAMM [1996]). Wherever possible, also data of the modules for additional biological (nutrients, primary production), chemical (metals, oxygen, organic pollutants) and sedimentological parameters and processes have been taken into account.

The capability of using these models operationally to determine both natural and anthropogenic changes on short and long terms and to make associated future predictions depends not only on the correct description of parameters and processes but to a large extent on the accuracy and coverage of data for initialisation, forcing and assimilation (continuous corrective up-dating). 
The NOWESP observational data set is intended to serve mainly three purposes:

1. determination of temporal and spatial variability on short and long time scales

2. the (direct) assessment of fluxes and budgets, and

3. providing the necessary inputs for numerical models, and data for the initialisation, calibration and validation of (and assimilation into) the models.

By assessing the available data for these purposes, specific data gaps have been identified and are detailed in this paper. In addition to the model data requirements described above, there are corresponding needs for

1. better implementation of algorithms for a number of processes

2. high performance computer techniques (reported separately (STELLING et al. [1996]).

The inter-relationship of these factors with model performance is considered.

\section{The NOWESP observational data set}

The many (mostly interpolated) data sets from different sources (RADACH et al. [1996b/c]) for the same parameter were merged into one comprehensive data set (GEKELER et al. [1996a]). The merged data sets for the ten NOWESP parameters were then used for interpolation of monthly distributions over the north-west European shelf to provide annual cycles of spatial distributions (GEKELER AND RADACH [1996b]).

Here the data sets are discussed with respect to coverage of the shelf during the annual cycle.

\subsection{Spatial and temporal distribution of climatolo- gical annual cycles}

There are not enough data available to cover the whole western shelf sea by "climatological" annual cycles derived from the NOWESP data set. For the North Sea, however, the annual cycles are sufficiently well represented. Most data are from coastal areas in the southern North Sea. Fewer data are available from the northern part of the North Sea (incl. the Northern Atlantic input), while very few data are available from the Irish Sea and hardly any west of Ireland.

The variability of different parameters over a period of at least 20 years has been shown by the temporal distribution at only 7 locations on the shelf. One time series was stopped. Others will be stopped in the near future.

To calculate concentration fields per month, all available data are utilized, disregarding the specific years, i.e. projecting all data into one "climatological" year. This is necessary to provide adequate data for this interpolation procedure.

Using the ERSEM model with 130 boxes, the number of observations per box goes down considerably in many boxes, ranging for phosphate, e. g., from 76 (box 93, north of Shetland Islands) to 15676 (box 70, German Bight) observations. The spatial heterogeneity of the sampling frequency is much larger than for the coarse resolution of the ERSEM setup with 15 boxes, where the mean observational coverage (1953 to 1995) is 975 data per box for phosphate, 628 data for nitrate, 319 data for ammonium, 674 data for silicate and 1014 data for chlorophyll.

The data coverage of the shelf is calculated using the constraint of having at least one observation in five different years with a spacing of less than $100 \mathrm{~km}$.

The basic hydrographic parameters temperature and salinity are needed

(i) to describe the environmental influence on the ecology

(ii) as boundary conditions for models

(iii) for (hydrodynamical) model calibration and validation

(iv) for monitoring the natural or anthropogenic variability on different time scales

It has been found during NOWESP that sufficient temperature and salinity data for these purposes (i-iv) are not available in the NOWESP area. Although the sea surface temperature (SST) data 
coverage has improved due to satellite IR images, subsurface temperature data as well as salinity observations in general are still scarce.

The spatial and temporal resolution for (i) depends mainly on nationally planned research and/or monitoring cruises, the international coordination of which is still insufficient. Only the IYFS (Int. Young Fish Survey (ICES)) provides more or less sufficient data coverage for the North Sea in February each year. Closer international coordination of research and monitoring programmes could solve this problem to a large extent.

Synoptic temperature and salinity boundary conditions, independent of model boundaries, are not available presently. Use of "climatic" boundary conditions on a yearly, quarterly or monthly basis causes problems because interannual variability in the eastern North Atlantic and adjacent regions of the Northwest European Shelf is strong.

The installation of a set of permanent stations in the eastern North Atlantic and/or the North Sea entrances is encouraged.

The coupling of operational Atlantic models to shelf models could also solve the problem, but it will take 5 to 10 years until such models are validated and operational.

Several data sets are available (e.g. FLEX 1976; NERC North Sea Programme, SKAGEX) which are used to check and calibrate models. Certain models are calibrated with tide gauge data or by hindcasting the transport and spreading of tracers (e.g. ${ }^{137} \mathrm{Cs}$ ) (Prandle and BeECHEy [1991]).

As long as no scientifically accepted rules exist on how to calibrate and validate models, the definition and creation of larger data sets for modelling use will have to wait.

Of all parameters, mean monthly temperature shows the densest data coverage, especially in the southern North Sea and the eastern Channel. Also the Skagerrak and, for a few months, the Kattegat can be covered by observations.

For the whole of the North Sea and partly also the adjacent English Channel, Skagerrak and Norwegian Sea in most months (except for January,
April, October, December), computed mean monthly salinity concentrations are available. The quality of these data is good.

The data coverage for mean monthly concentration of phosphate is irregular over the year.

The coverage of the North Sea by silicate observations shows a pattern which is very similar to phosphate.

Nitrate is also measured nearly as frequently as phosphate, and the North Sea shows a similar coverage with data.

Only in November are nitrite concentrations sufficiently frequent to cover the whole North Sea (> 45 observations per grid point). Good coverage elsewhere is restricted to the southern coastal areas (all months), the northern area west of Norway, Skagerrak and parts of the Kattegat.

For ammonia the data coverage is relatively good along the continental coasts, from the English Channel to the German Bight, with 30 to 40 data per grid point. However, the German Bight is less well covered than the Belgian and Dutch coastal strip, being widely devoid of data in January, October and December.

Likewise, the chlorophyll concentration can only be determined in restricted areas of the shelf, in the continental coastal strip and in the north-western North Sea during most months.

For particulate suspended matter the data density is sufficient only in the southern North Sea close to the continental coasts, with 35 to 45 data per grid point. The area extends to the Dogger Bank only in May.

The temporal distribution of observations is very heterogeneous except for the data sets that were obtained in long-term monitoring programmes. Good examples of long-term time series (more than 20 years) are the monitoring data from Rijkswaterstaat off the Dutch coast, the long time series at Helgoland, the data from Stations E1, E4 and E7 in the Channel and from Port Erin on the Isle of Man (GEKELER AND RADACH [1996a]). The NOWESP data set has a sufficiently fine temporal resolution for the creation of time series of monthly means at only eight sites for the years 1975-1993 (RADACH et al. [1996c]). One of the series ( $E$, in the channel) 
stopped in the nineties, and other series are under pressure to be stopped as well.

The analysis of the data with respect to temporal resolution shows that a temporal resolution of less than one month is possible only in very special cases, e.g. the Helgoland time series and the Fladenground experiment.

\section{The NOWESP model data}

Additional data (to be used in modelling exercises) may be necessary for two main purposes:

- to improve estimates of fluxes and budgets on the basis of the (collected) field data and existing model data (over annual cycles on the scale of the whole North West European Continental Shelf).

- to improve the quality of the numerical models by providing data for model calibration, validation, data assimilation and boundary conditions.

Within the ecosystem modelling MAST project ERSEM, the semi-baroclinic general shelf sea circulation model HAMSOM was used for simulating circulation on the north-west European shelf over nearly forty years (1955-1994). The resulting current fields and derived transports (PÄTSCH AND RADACH [1996b]) were used to simulate the eutrophication of the North Sea (PÄTSCH AND RADACH [1996a]), and they were used in NOWESP for estimating the advective fluxes across the shelf boundaries (LAANE et al. [1996b]).

An overview of the different models used by the NOWESP partners is given by Yu et al. [1995] and an intercomparison is given by SMITH et al. [1996].

\section{Observational data needs}

\subsection{Fluxes and budgets}

The acquisition of shelf data by NOWESP should by no means be stopped. More hidden data must be brought to daylight and made available to all interested researchers.

It is recognized that atmospheric deposition is an important source of a number of parameters in sea water. The uncertainty concerning the amounts of atmospheric deposition of compounds on the shelf is high as compared to the other sources.

At the current stage, the calculation of fluxes and budgets for the North-West European shelf is based on seasonal means of the concentrations and long-term records of water flow from models (1955-1993). Fluxes ('rates' of processes) are a more stringent basis for model calibration than pool sizes ('states'). Unfortunately, process rates are not often measured in routine programmes, while more dedicated research programs all use different methods and techniques. For modelling purposes there is a strong need to define key processes in nutrient turnover and to establish techniques that can be used in routine programmes. As a promising tool, nutrient sensors with a high resolution in time combined with high analytical precision could be used to detect the effect of rapid transformations from which, in turn, actual process rates could be estimated.

The EU should promote the development of such reliable 'smart sensors' to be applied in permanent mooring arrays or in combination with, e.g., continuous plankton recorders (CPR).

The variability of fluxes caused by variable water flow can be described in this way. However, little is known about the long-term variability in the concentration of different parameters. This aim could possibly be reached by combining all existing data that are presently held in different data bases with hitherto undiscovered data in institutes and laboratories.

The model simulations cannot be completely validated as being consistent with observations. Compared to the riverine and Atlantic input of different compounds to the shelf, the atmospheric deposition is less known. 
There seems to be a great potential for synergistic combination of modelling and survey data to determine (by inverse modelling) source concentrations (Prandle et al. [1996]; McManus and Prandle [1994], McManus and Prandle [1996]).

There is, in fact, a need for "mixed" data bases, containing both measured values (of e.g. $S$ and $T$ ) and long-term reliable (simulated) and validated currents.

\subsection{Boundary conditions}

The results of fine-grid model shelf flux calculations will be improved by a better description (in both spatial and temporal domains)of different parameters at the boundaries of the shelf and by inverse modelling.

Remote sensing of different parameters by satellites will be a powerful tool to collect a synoptic data set, geographically distributed over the shelf to calibrate or validate shelf models.

Models need several categories of data: data for forcing at the boundaries and in the interior, data for calibration, validation and assimilation.

Different boundaries can be distinguished: the ocean boundary at the shelf edge, the continental boundary (inflowing rivers), the sea-bed, and the air-water interface.

In the present models the boundaries are very often rough, and because of lack of data interpolated data are used. Since the boundary conditions often substantially influence the model parameters of the whole computational domain, better knowledge of these conditions would improve the quality of the models.

\subsubsection{Ocean boundaries}

Together with wind and thermohaline driven currents, tidal flow is one of the major driving forces of the North sea shelf circulations. Accurate simulation/ prediction of the water movements largely influences the quality of the results of other flux mo- dels. At the ocean boundary of the hydrodynamic models, tidal elevation (sea level) data are normally prescribed. Therefore, the accuracy of reconstructing the ocean boundary tides is of major importance for the shelf sea flux modeller. Presently, data can be obtained either from the analysis of recorded time series, e.g. IOS/ IAPSO (SMITHSON [1992]), or can be generated by (global) ocean models, SCHWIDERSKI [1983]. Although it is often recommended to use measured data when prescribing boundary conditions, it is common practice either to link the shelf model to an ocean model, e.g. the German model (KLEINE [1994]), or to use the results of a global ocean model (Yu [1993]). This is attributable to the paucity of tidal data along the shelf break as compared to the relative abundance along coasts and at offshore structures. The discrepancies between results from the same model using different open boundary data sets (model simulations and measurements) are not negligible (YU AND DECOUTTERE [1996]).

The performance of the hydrodynamic and transport models can be improved by more information on (the variability in):

- inflowing water masses in the Dover Strait and in the Fair Isle Passage

- salinity, temperature and SPM (suspended particulate matter) data at the model boundaries

- Atlantic input of nutrients

- water exchange with the Baltic Sea

Long-term simulations of ${ }^{137} \mathrm{Cs}$ dispersion have shown the effect of topographic steering on residual streamlines. Pathways following the shelf edge have been validated by drifting drogues. An effective "flushing time" of 5 years for the N. W. European Shelf has been indicated.

Recently, net tidal and wind-driven fluxes of sea water through the Dover Strait have been determined by combining HF radar measurements of surface currents with ADCP measurements of vertical current profiles. The observations have been compared with similar derivations from various numerical modeling simulations (PrANDLE et al. [1996]).

Tidal data are recorded relatively easily and, defined as being constant through time, allow re- 
sults from non-synoptic measurements to be readily combined. By contrast, salinity, temperature, suspended matter (SPM) and nutrients are transient, and short-term measurements cannot be readily combined, while long-term observations are rare. To obtain these data, expensive measurement campaigns and the use of rather sophisticated tools and equipment are in fact required.

The use of recently developed remote sensing techniques can improve the situation, especially spatial resolution at the surface.

In those areas where exchange of water masses with the Atlantic Ocean takes place, the coverage of nutrient data with respect to both time and space is not very dense (LAANE et al. [1996b]). Since the Atlantic Ocean is by far the largest source of nutrients for the NW European shelf seas, lack of data on this oceanic exchange places severe restrictions on any nutrient budgeting and modelling exercise.

It is, therefore, recommended to set up a European network of institutes which are responsible for monitoring nutrient concentrations at the Ocean-Shelf-Boundary on a regular basis, in combination with hydrographic measurements of water movement.

To explain the long-term and seasonal variability of different parameters on the shelf, the contribution of sea-bottom and land-sea interaction (anthropogenic compound) to the total variability must be studied.

\subsubsection{Air - sea interaction}

The atmosphere and the water body form a coupled thermodynamical system. Changes in one system (e. g. the wind speed) will lead to changes in the other system (e.g. wave generation). Depending on the solubility of the gas considered, the exchange will be mainly controlled in the water phase (e. g. carbon dioxide) or in the air phase (e.g. water vapour). It is known that exchanges across the air-sea interface depend on wind speed, but cannot solely be described by parameterization as a function of wind speed only. A complete pheno- menological description is still lacking, but an appropriate parameterization of the transfer processes across the air-water interface will contain information about the wind, waves, and turbulence field in the water column. It is, therefore, necessary to measure (and model) the different parameters affecting the interaction. These parameters include wind speed, wind-stress, cloudiness, relative humidity, water vapour fluxes, air-sea temperature difference, $\mathrm{CO}_{2}$-concentration, $\mathrm{CO}_{2}$-flux, atmospheric inputs of metals $(\mathrm{Pb}, \mathrm{Al}, \ldots)$ and organic micro-pollutants, wave spectra, white capping distribution, and the turbulence field in the upper water layers.

It is important to have a number of point measurements using well established measurement techniques, as well as measurements with a wider (but still high resolution) spatial coverage (satellites, air-borne techniques, land based and ship radars).

Atmospheric input of nitrogen is very important for plankton dynamics, but measurement data are hardly available. There exist simulation models for atmospheric nitrogen transport and modification, but these models need validation.

\subsection{Driving forces}

With respect to time scale, two types of models are used: "long-term" ("climatological") models, aiming at simulating long-term changes and budgets (statistically averaged parameters like tidal constituents, annual means, annual budgets) and "short-term" ("episodical") models simulating variations and fluxes during certain "episodic" events or periods (e.g. storms).

Applications involving episodic events are complicated by the paucity of synoptic data sets to initialise, force and verify simulations. Continuous development of autonomous sensors and the establishment of related monitoring networks should overcome this problem. One needs:

- time series of wave spectra (wind sea and swell) and/or integrated spectral parameters such as 
significant wave height and mean direction, among others.

- time series of wind speed (east and north components) in order to interpret model results, and to produce wave data from wind data if measurements are not available.

Analysed wind fields produced by meteorological offices are available and are quite reliable. A network of wave gauges with real-time assimilation possibilities, however, is not available. Again, remote sensing techniques offer possibilities for assimilation of wind and wave data. Hindcast wave data also exist, such as those delivered by the E.U. project WASA, which produced a data set of hindcast wave spectra and integrated spectral parameters for a period of 40 years (1955-1994); these data should become available soon (end of 1996)

For ecological models, the availability of several driving forces is required: hydrodynamical forcing, solar radiation forcing, and interior forcing caused by the truncation of the biological system. The biological closure problem demands fields of observations on the shelf, e.g. of zooplankton biomass or of the biomass of higher predators.

Remote sensing techniques offer possibilities for assimilating wind and wave data.

\subsection{Data of water column properties}

Knowledge of a turbulence quantity is urgently needed to link phytoplankton processes in, e. g., biological oceanography to physical oceanography.

A parameter largely neglected but very important for life in the sea is turbulence and advective mixing. These data will be essentially "model" data obtained for episodical events. Recent advances in instrumentation now provide direct measurements of profiles of turbulent dissipation rates. These are needed to calibrate and validate the models.

Higher marine trophic levels are not very important for energy transfer and carbon transformation processes. Nevertheless, for a full understanding of the marine ecosystem these levels have to be studied as well. Commercial fishes have been studied and quantified traditionally by fisheries institutes whereas marine mammals and birds are sometimes part of monitoring programmes, or are studied by environmental or natural protection institutes. The need to have these data on the same time scale as the previous ones is less pressing or even nonexistent because of their longer generation times. Here mortality and fertility are important processes in dynamic models. Moreover, the explicit behaviour of most of these species makes them difficult to treat in ecological models, except as boundary conditions/values.

\subsection{Biological data}

For ecological models the list of state variables may be very long, and it is not realistic to obtain shelf-wide data coverage from surveys for, e.g. picophytoplankton, nanophytoplankton, bacteria, microzooplankton, mesozooplankton and higher trophic levels. For these state variables, also in the near future, only selected and very specified attempts to understand the system will be possible. The greatest chance to improve the existing data sets would lie in merging existing data sets. Although "merging" has some limitations, it is by far the cheapest way of obtaining additional data.

The ecological data in NOWESP comprise phytoplankton and zooplankton, apart from related chemical data. Phytoplankton data are available in different forms: as chlorophyll-a, as species composition (occurrence of different species or species groups in numbers per litre), or in case of CPR (Continuous Plankton Records) data in terms of abundance classes of the larger phytoplankton cells, due to the mesh-size used. In a few cases data were available as real biomass data (phyto-C) based on cell counts and cell volumes and conversion to carbon.

Apart from phytoplankton biomass data, as a main process parameter, primary production data are available. Due to the lack of a consistent stan- 
dard method, this data set is diverse: most of the data are in the form of P-I relationships (Photosynthetic rates against irradiance), but sometimes we have results of in situ measurements or potential production data (maximal photosynthetic rate at saturating irradiance). Conversion of one data set into another one often is not possible without large or unknown errors.

Therefore, additional data are often needed to make such conversions (vertical attenuation coefficients, or Secchi disc values, global irradiance, day length).

The need for observational biological data is apparent. There are large gaps in temporal and spatial resolution and coverage. Most important, however, is the consistency of the "ecological" data set. There is a strong need for a selection of ecological data at a set of stations on the shelf without gaps in observations and with consistency in the frequency of data collection. A European effort should be considered to set up a network of stations where a limited, selected set of parameters is measured at exactly the same time and on a long-time basis to be able to use them for modelling, for interpretation of long time natural changes in the marine environment and changes due to human interference (eutrophication, pollutants, climatic changes, biodiversity changes).

Phytoplankton, species composition of dominant species or larger taxonomic units which use different types of nutrients, phytoplankton biomass by chlorophyll (there is at the moment no simple alternative); primary production as the most basic process in the sea; as accompanying parameters inorganic nutrients should be measured at the same stations with the same frequency ( $\mathrm{N}, \mathrm{P}$ and $\mathrm{Si})$, as well as a parameter to indicate light conditions in the sea. The explanation of zooplankton distribution and changes in abundance during NOWESP proved to be very difficult; the scale of CPR observations is very good and the temporal resolution is also relatively good; however, no accompanying parameters are measured at present, and the correla- tions in NOWESP therefore are based on data from other nearby stations at not exactly the same time. This may strongly hamper direct comparison of, e. g., chlorophyll and zooplankton. Moreover, zooplankton comprises a very diverse trophic group and should be subdivided to discriminate between herbivores, carnivores and other groups. In principle, this is already possible.

Estimates of grazing pressure due to zooplankton is missing, but it is a process parameter which cannot yet be measured in standard monitoring programmes. Such links between different levels in the food web need to be established in order to find out whether these links are strong or negligible. The same holds also for direct links between nutrients and phytoplankton. In the latter case absolute nutrient levels as well as their ratios are of importance as an explanation of observed changes in species composition of phytoplankton. As soon as foodweb relations, e. g. for ecological models, come into sight, measurements of the microbial food web are needed. Most of the energy transfer in marine ecosystems goes through this part of the marine foodweb which is difficult to observe and to measure. Presently new techniques are becoming available to study this part of the food web as well. These measurements should contain bacterial biomass and activity.

\subsection{Nutrients}

Regeneration of nutrients through mineralisation of plankton material occurs mainly in the water column where they become directly available to the primary producers. A small part of the organic material survives, however, long enough to be transported to other areas of the shelf. The transport of particulate matter (especially coarse-grained) with the associated nutrients and organic compounds focuses on distinct deposition areas, e.g. the inner German Bight and the Skagerrak. Here, enhanced mineralisation may occur, and nutrients originating from a large area may be transported to a particular (distant) location. As a consequence, enhanced regenerative production may appear, particularly in 
the summer months. Alternatively, these depocentres provide the main sites for burial of nutrients and carbon in the sedimentary record which is their main loss mechanism on longer time-scales. Without proper knowledge of the time-scales of the repeated sequence of transport-deposition-resuspensiontransport of suspended particulate materials and of the transformations of associated nutrients and carbon, any modelling attempt to predict changes over longer time-scales (years to several decades) is likely to fail.

Research programs investigating the transport of suspended matter, nutrients and carbon to determine the relation between nutrient status and primary production in different areas along the main transport route on the shelf should be strongly encouraged.

\subsection{Suspended particular matter (SPM)}

In order to run numerical SPM transport models, the above mentioned boundary conditions and the following bed and sediment data as well as information about biological activities are needed:

- the actual topography of the model area with a sufficient resolution $(1 \mathrm{~km})$, presently not generally available on a shelf-wide scale;

- settling velocities of SPM. No general information is available on their spatial and temporal distribution;

- initial 2D or 3D distribution of the SPM concentration; a rough approximation is sufficient because the model simulation has to start some time before the time period of interest;

- horizontal distribution of the fine fraction $<20$ microns and $<63$ microns in the sediment (upper $20 \mathrm{~cm}$ ): sufficient knowledge is not available;

- biological parameters can only be estimated very roughly, but their seasonal and spatial distributions have to be known to quantify several bottom processes:

- filtration rate of suspension feeders,

- activity of deposit feeders,
- bioturbation rate;

- critical values of the bed shear stress are essential to the bottom processes deposition and erosion, their dependencies on the settling velocity of SPM (for deposition) and their spatial distribution (for erosion) are not yet available;

- bedforms (ripples) influence the erodability of the sediment; little information available;

- trawling frequency data are necessary because of additional erosion events in some areas; data are hardly available;

- time series of the distribution of SPM concentration and corresponding settling velocity spectra at the open sea boundaries (essential model input);

- time series of SPM concentrations at certain locations inside the model area (validation of model results);

- accumulation rates of deposited material (validation of model results).

\subsection{Temperature $(T)$ and Salinity $(S)$}

\section{$6 \quad$ Modelling needs}

\subsection{Needs for physical modelling}

As the ecological model results depend strongly on the hydrodynamical forcing, there is a strong need for a detailed and high resolution Continental Shelf Model(s) verified over a long period of time (e.g. 20 years) which is fully compatible with the observational data.

Although such an exercise has never been carried out for the entire NoWEShelf, it has been done for particular areas (e.g. Rhine mouth, German Bight, ...). The (inter)comparison of model output from different hydrodynamical models is very important for understanding the extent to which ecological model results are influenced by the peculiarities of the hydrodynamical model used. A first attempt in this direction was made by SMITH et al. [1996] who compare the available model simulations made with HAMSOM (from ERSEM) to the physical part of NORWECOM and the hydrodynamic model from POL. 


\subsection{Needs for ecological modelling}

Presently, there exist a number of ecological models for the North Sea which have common goals (SKogen et al. [1995], MoLL [1995]). Although the objectives of the models are nearly the same, a comparison of model setup and results has never been made.

A compilation of all substantial model runs of the main ecological models applied to the shelf and a comparison of their results would be a worth-while task. Furthermore, an evaluation of the different model outputs with respect to their estimation of fluxes across the shelf is feasible and should be done.

\subsection{New monitoring strategies}

The development of satellite and air-borne remote sensing techniques (R.S.) should provide synoptic SPM data for a large area, at the seasurface. In-situ buoys and bottom platforms will be necessary to both calibrate the R.S. and provide data on vertical gradients in the water column.

Remote sensing: need for European cooperation

Consistent, synoptic distributed data (obtained by remote sensing techniques) are extremely useful for model calibration and validation (for SPM, chora, salinity and temperature). However, time series are available only at a very limited number of sites. Through the use of modern (air-borne) remote sensing techniques, nearly instantaneous data coverage may become available for the whole shelf area.

Up to now, the qualitative relation with the images of R.S. and actual field concentration is sufficient. Relative gradients can be described. However, the direct transformation from images to concentration is still difficult.

The design of an operational observing system involves quantification of the improvement in predic- tability as a function of the number and nature of observations. Observational System Sensitivity Experiments (OSSE) need to be formulated involving nested models with geographical interdependency. Although predictions within the coastal component are ultimately reliant on assimilated data from the external monitoring network, the sensitivity of this network can initially be explored by substituting synthetic model data (with observational 'error bars' introduced). Such experiments will be very useful for determining the investment plan for monitoring networks.

While the technical and geographical constraints of operational oceanography require intensive collaboration, the requirement to develop coastal observations and modelling locally will remain.

Wind fields, atmospheric processes, large scale ocean currents, oceanic heat transport, changes of sea level, pelagic species all need to be measured and analysed on the full European scale. Remotely sensed observations from satellites are necessarily consistent across Europe and the adjacent sea and ocean areas. Thus, processing of remotely sensed space data is naturally an operation to be conducted on the full European scale. However, it would be uneconomic for numerous different agencies to run duplicate large scale models, or to repeat observations which only need to be made once. Thus a European design for operational oceanographic infrastructure and international cooperation is required.

Moreover, such investment generally involves international co-operation (satellites, air-borne sensing, ships-of-opportunity (ferries), real-time data exchanges between coastal monitoring networks etc.), and hence requires strategic, long term planning.

New monitoring strategies

A new integrated multi-disciplinary monitoring strategy and approach is necessary. It should result in a set of procedures on data collection 
(sampling strategies, chemical analysis), interpretation (environmental knowledge, statistics) and assessment which are logically connected to form a strategic framework and which are cost effective (LAANE [1995]).

Monitoring water quality is an essential tool in environmental research and policy: its purpose is to check whether certain policy measures result in the expected environmental changes. It is certainly most relevant for the Oslo and Paris Commissions.

There are several national and international monitoring programmes running at the moment, e. g. chemical monitoring, the ASMO and Joint Monitoring Programme and biological monitoring, the Joint Young Fish surveys and the ICES benthic surveys. From the NOWESP data base, however, it can be seen that every country and even every authority has developed its own monitoring strategy, taking into account its own goals, priorities and tradition. As a consequence, data on rivers and seas from different sources may be very difficult to compare and/or integrate into a common database. So, although billions of dollars have been spent worldwide on monitoring rivers, estuaries, coastal zones and seas, it still is not always easy to say whether water quality is getting better or worse: we are datarich and information poor LAANE [1990].

In the past, monitoring strategies have often been based on relatively simple approaches, for example on a relatively dense distribution of sampling locations. However, the data can be used to calculate the variability and precision. Today, these empirical approaches are no longer acceptable. New monitoring strategies must be developed, which cope with the financial constraints, the nature of (new toxic) substances involved, and with the biological effects observed. They should also take into account the fact that the main source of substances has shifted from direct sources (e.g. industries) to indirect or diffuse sources (e.g. aquatic sediments, traffic, atmosphere and run-off).

Results of remote sensing and water quality models must be integrated into national and international monitoring programmes.
Water quality monitoring data from different countries are stored in the NOWESP data base. No synoptic picture can be obtained from these data. Integration of results from remote sensing images and water quality models will enhance the quality of the results in each respect.

Biomarkers and bioassays are essential and cost-effective tools in water quality monitoring to measure effects of substances.

Data in the NOWESP data base are based on field and model concentrations of different substances. Most of the field data are from national monitoring campaigns which started in the seventies. Up to now, monitoring has focused on measuring the concentration of compounds. However, this does not say anything about the effect. The causal relation is difficult. More and more environmental monitoring programmes measure sub-lethal effects by means of biomarkers and bioassays.

\subsection{Better knowledge of physical processes and their interactions}

Apart from a need for better, more, and more consistent data, there is an urgent need for a better understanding of physical processes in order to improve the predictive capability of the models. The limits to the predictability of such models, and likewise of linked sub-models operated locally for specific estuarine/coastal applications, will be determined by the accuracy of the algorithms and associated parameters representing basic processes.

The intrinsic link between operational meteorology and oceanography is highlighted by the primary user's need identified by the US Coastal GOOS, i.e. for accurate mid-range weather forecasts. To understand ecological processes the physical processes should be known very well, e. g.: 3D stratification (e.g. fronts) which, together with the thermocline, is very important for ecological processes. Other processes that should be known 
better are: ocean surface shear stress as a function of the wind field, air - sea drag (due to wind and waves), interaction of waves and currents, wave generated turbulence/ bottom friction, effects of currents on wave propagation, and wave induced resuspension of SPM and related predator activity.

\subsection{Needs for detailed inputs}

The quality of the model results depends greatly on the accuracy of inputs: topography, detailed wind forces (better than every $100 \mathrm{~km}^{2}$ !), wave information (wind waves and swell) for SPM models, areal distribution of bed forms and boundary conditions on tides, water fluxes, S, T and SPM concentrations, atmospheric inputs

\section{General recommendations for E.U. data collection and data management policy:}

Data centre(s)

NOWESP has compiled a vast quantity of existing data from the north-west European shelf, a focused task so far without precedence. However, there may exist additional data which were not known or not easily accessible at the time. These "sleeping" data sets should also be compiled and put together with all existing files. The cheapest way to complete the compilation of data could be by funding scientists who have such data, to enable them to provide their data in an up-to-date digital form in collaboration with national and international data centers.

It is highly recommended that one, or a few national and international data centres or agencies should be chosen (and properly supported for this purpose through a long-term project) by the E.U., where all available observational data are collected, stored, maintained (i. e. regularly updated) by the providers of the data, and made available to the researchers. Especially data delivered to the E.U. within the framework of E.U. projects should be made readily available to all potential users.

\section{Quality control of data}

International agreement must be reached on quality control procedures and quality standards for data to be stored in data bases.

For ongoing projects and all new projects, the quality of data has to be ensured by the originator before delivering the data sets to any data centre, according to a generally approved quality control procedure and quality standards. The name of the originator and a report on the methods used have to be provided together with the data. They have to be stored with the data and kept at the data centres to allow tracing back of the data. Nationally as well as internationally funded projects should include the contract requirement to deliver the quality controlled data sets obtained within the project to the national (or international) data centres.

It is realized that those data have economic and political value (e. g. for fishery policy, dumping policies, etc ...). Proper arrangements should, therefore, be made to preserve the economic value of the data to their "owners" without compromising use of the data by researchers, or to allow for unnecessary duplication of data collecting efforts. The scientific community could be ensured free access to the data, e. g. two years after termination of the project.

\section{Complementary data collection}

What is really needed is concentration fields for temperature, salinity, nutrients, suspended matter and chlorophyll (and many more parameters) that can be called "climatological" fields. For this purpose at least one survey on the whole European shelf is needed for each month during at least five years, with a proper spatial resolution, e. g. $1^{\circ}$ by $1^{\circ}$, and at least in those areas where climatological data are now totally lacking. From the modelling 
point of view, an alternative would be the availability of data from sufficiently representative fixed stations on the shelf, with weekly sampling for several years.

It should be realized that there are hardly any data available on the shelf boundaries. West of the British Isles, practically no information is actually available. These data may be available somewhere, or become available in the future within ongoing projects. They should be integrated into the existing data bases. Targeted projects should be set up to collect such missing essential data.

Therefore, one should consider a European effort to set up a limited network of stations, especially at the shelf edge, where a limited, selected set of parameters is measured on a long-time basis (time series) for use in modelling, for interpretation of long-term natural changes in the marine environment and changes due to human interference (eutrophication, pollutants, climatic changes, biodiversity changes).

\section{Coordination of data collection}

Occasionally, initiatives are taken in E.U. member states to collect particular data in particular areas during particular periods of time. The E.U. could foster the coordination of nationally organized measuring campaigns in Europe. It is particularly important to have all data collected and quality checked according to generally agreed procedures and to store the data in a proper digital format in a recognized data base.

\section{Collection of areal distributed data}

Methodologies should be promoted to collect areal distributed data sets through remote sensing (satellite or aircraft borne) techniques. Cooperation with other E.U. programs and EUROGOOS (association of agencies from E.U. member states) should be encouraged.
Modelling needs

The formulations of basic physics should be improved: turbulence must be simulated in a way which more closely represents nature. There is a need for a well validated, detailed shelf circulation model which represents the measured data properly during long-term simulations. Tides must always be included because they are important for mixing.

Coupling of hydrodynamic circulation models with numerical wave forecasts is recommended because wave forecasting is essential for SPM modelling. There may be a connection to the E.U. project PROMISE.

Internal waves which usually are not included in general circulation models should ideally be included, but it is not yet clear how this should be done (deterministic or stochastic modelling? parameterization?); also heat fluxes should be included.

A global, detailed North Atlantic ocean circulation model should be developed to provide proper boundary conditions at the shelf edge.

The physics of exchanges at the shelf edges, between the ocean models and the shelf models should be studied and better formulated.

Computational software and hardware needs should be addressed for all purposes, but the required strategy should link end user products (EUROGOOS) backwards through requisite models, monitoring, process studies, and distinguish between what is possible now, in the short-term, and (possibly) in the distant future. The latter generally translates to physics, chemistry and biology, with chemistry staged between conservative dissolved tracers (salt, ${ }^{137} \mathrm{Cs}$ ) and non-conservative particle reactive substances. Clearly the monitoring/ modelling requirements for these differ. Likewise differentiation based on the nature of sources/sinks (ocean, atmospheric, estuarine, etc.) should be taken into account. 


\section{References}

BackHaus, J. O., 1989: The North Sea and the climate. Dana 8: 69-82.

Beukema, A. A., G. P. Hekstra and C. Venema, 1986: The Netherlands Environmental Policy for the North Sea and Wadden Sea. Environmental Monitoring and Assessment., 7(2): 117-156.

Bot, P., W. van Raaphorst, S. Batten, R. Laane, K. Philippart, G. Radach, A. Frohse, H. Schulz, D. van den EYNDE AND F. COLIJN, 1996: Comparison of Changes in the Annual Variability of the Seasonal Cycles of Chlorophyll, Nutrients and Zooplankton at Eight Locations on the North-West European Shelf. This Volume, 349-364.

EIGENHEER, A., W. KüHN AND G. RADACH, 1996: On the sensitivity of ecosystem box model simulations on mixed layer depth estimates. Deep-Sea Res. (In print).

GEKELER, J., AND G. RADACH (Eds.), 1996a: NOWESP Data Sets. Technical Report. University of Hamburg, Third Edition, July 1996.

GeKELER, J., AND G. RADACH, 1996b: Gridding of the NOWESP data sets. Monthly mean concentrations of temperature, salinity, nutrients, suspended matter, and chlorophyll on the north-west European shelf. Technical Report.

KLEINE, E., 1994: Das Operationelle Modell des BSH fur Nordsee und Ostsee, Konzeption und Übersicht. Bundesamt fur Seeschiffahrt und Hydrographie, Hamburg.

Laane, R., W. van Leussen, G. Radach, J. Berlamont, J. SÜNDERMANN, W. VAN RAAPHORST, AND F. COLIJN, 1996a: North-West European Shelf Programme (NOWESP): An Overview. This Volume, 217-230.

Laane, R., E. Svendsen, G. Radach, G. Groeneveld, P. Damm, J. Pätsch, D. S. Danielssen . L. Føyn, M. Skogen, M. Ostrowski and K. J. M. Kramer, 1996b: Variability in Fluxes of Nutrients $(\mathrm{P}, \mathrm{N}, \mathrm{Si})$ into the North Sea from the Atlantic Ocean and Skagerrak Caused by Variability in Water Flow. This Volume, 401-420.

LAANE, R. W. P. M. AND B. J. E. TEN BRINK, 1990: Data rich, information poor, the modern monitoring syndrome? Land and Water International, 68, 12-16.

Laane, R. W. P. M., J. van der Meer, A. de Vries and A. VAN DER GIESSEN, 1990: Monitoring the Progress of Attempts to Reduce Nutrient Load and Inputs of Certain Compounds in the North Sea by $50 \%$. Environmental Management, 124(2), 221-227.

LaAne, R. W. P. M. and K. J. M. Kramer, 1995: Future developments regarding toxic substances in the coastal zone. Proceedings EERO workshop, GKSS Hamburg, 90-94.

Lenhart, H., J. PÄtsch and G. Radach, 1996: Daily nutrient loads for the European continental rivers during 1977-1993. Discharges and loads of rivers entering the North Sea. Technical Report. ZMK-Berichte (in print).

McManus J. and D. Prandle, 1994: Comparisons Bet- ween Observations and Model Simulations of Dissolved Trace Metal Concentrations in the Southern North Sea. Marine Pollution Bulletin, Vol. 28, No. 7. pp. 451-455.

McManus J. AND D. Prandle, 1996: Determination of Source Concentrations of Dissolved and Particulate Trace Metals in the Southern North Sea. Marine Pollution Bulletin, Vol. 32, No. 6. pp. 504-512.

MolL, A., 1995: Regionale Differenzierung der Primärproduktion in der Nordsee: Untersuchungen mit einem drei-dimensionalen Modell. Dissertation - Berichte aus dem Zentrum für Meeres- und Klimaforschung, Reihe B Ozeanographie, Nr. 19, $151 \mathrm{~S}$.

NOWESP, 1996: The North-West European Shelf Programme, 3rd annual progress report, MAS2-CT930067

PÄTSCH, J. AND G. RADACH, 1996a: Long-term simulation of the eutrophication of the North Sea. JSR.

PÄTSCH, J., AND G. RADACH, 1996b: Hydrodynamic simulations of the North Sea circulation over four decades using HAMSOM. Hydrodynamical forcing for the applications of ERSEM to the North Sea. Technical Report. ZMK-Berichte.

Prandle, D. AND J. BeEchey, 1991: Marine dispersion of Caesium 137 released from Sellafield and Chernobyl. Geophysical Research Letters, Vol. 18, No. 9, pp. 1723-1726.

Prandle, D., G. Ballard, D. Flatt, A. J. Harrison, S. E. Jones, P. J. KNIGHt, S. Loch, J. McManus, R. PlayeR, A. TAPPIN, 1996: Combining modelling and monitoring to determine fluxes of water, dissolved and particulate metals through the Dover Strait. Continental Shelf Research, Vol. 16, No. 2, pp. 237-257.

RADACH, G. AND J. GeKELER, 1996a: Lessons Learned from Setting up the NOWESP Research Data Base: Experiences in an Interdisciplinary Research Project. This Volume, 231-240.

RADACH G. AND J. GeKELER, 1996b: Annual Cycles of Horizontal Distribution of Temperature and Salinity, and of Concentrations of Nutrients, Suspended Particulate Matter and Chlorophyll on the North-West European Shelf. This Volume, 261-298.

RADACH, G., J. GeKeler et al., 1996c: The NOWESP Research Data Base. This Volume, 242-260.

Radach, G., J. PÄtsch, J. GeKeler and K. Herbig, 1996b: Annual cycles of nutrients and chlorophyll in time in the North Sea. Techn. Report. ZMK-Bericht 20.

Skogen, M. D., E. Svendsen, J. Bertsen, D. Aksnes and K. B. ULVESTAD , 1995: Modelling the primary production in the North Sea using a coupled 3 dimensional physical chemical biological model. Estuarine Coastal and Shelf Science (accepted).

SMITH, J., P. DAMm et al., 1996: An Investigation into the Variability of Circulation and Transport on the NorthWest European Shelf Using Three Hydrodynamic Models. This Volume, 325-348. 
SMITHSON, M. J., 1992: Pelagic tidal constant 3.'Proudman Oceanographic Laboratory, International Association for the Physical Sciences of the Ocean (IAPSO) of the International Union of Geodesy and Geophysics.

SCHWIDERSKI, E. W., 1983: Atlas of the ocean tidal charts and maps. Marine Geodesy.

Stelling, G., D. Roose, B. P. Sommeijer, P. J. Van den HOUWE, J. KOK, H. X. LIN, K. TAN, 1996: New generation Shelf Flux Models. Unpublished manuscript.

Van Leussen, W., G. Radach , W. van RaAphorst, and F. COLIJN, 1995: NOWESP: Investigations on the variability and trends in the north-west European shelf. ICES Symposium Aarhus 1995.

Van Leussen, W. ANd G. RADACH, 1996: NOWESP Manual on Statistical Analysis Techniques. Technical Report. RWS, Den Haag, Second Edition, November 1996.

Visser, M., S. Batten, G. Becker, P. Bot, F. Colijn, P. Damm, D. Danielssen, D. van den Eynde, L. Føyn, A. Frohse, G. Groeneveld, R. LaAne, W. van RaAphorst, G. Radach, H. Schultz, and J. Sündermann, 1996: Time Series Analysis of Monthly Mean Data of Temperature, Salinity, Nutrients, Suspended Matter at Eight Locations on the North-West European Shelf. This Volume, 299-324.

DE VRies, A. AND H. C. KLAVers, 1994: Riverine fluxes of pollutants: monitoring strategy first, calculation methods second. European Water Pollution Control, 4(2), 12-17.
Ward, R. C., J. C. Loftis And G. B. Mcbride, 1986: The "Data rich but information poor" syndrome in Water Quality Monitoring. Environmental management, 10(3), 291-297.

Ward, R. C., J. C. Loftis AND G. B. Mcbride, 1990: Design of water quality monitoring systems, Van Nostrand Reinhold, New York, $231 \mathrm{pp}$.

Yu, C. S., J. Monbaliu, J. Berlamont, 1995:, NOWESP Formulation of the balance equations. Scientific report C/MAST-II/NOWESP, K. U. Leuven, Belgium. January 1995.

Yu, C. S., 1993: Modelling Shelf Sea Dynamics and Estuarine Circulations, Ph.D. Thesis, Dept. of Civil Eng., K. U. Leuven.

Yu, C. S., J. Monbaliu And J. Berlamont, 1995: Review of the existing shelf flux models of the NOWESP partners. Scientific report, EC/MAST-II/NOWESP, K. U. Leuven, Belgium.

Yu, C. S AND C. DeCouttere, 1996: Comparison of different data sets used for the construction of the forcing tides at the open boundary of a north-west European shelf model, Internal Report, Laboratory of Hydraulics, K. U. Leuven. 